\title{
Contexto sonoro expandido en el pensamiento equinoccial contemporáneo
}

Expanded Sonic Context in Contemporary

Equinoctial Thinking

Norberto Bayo

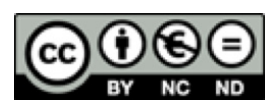

Esta obra está bajo una licencia Creative Commons Reconocimiento-No comercial-Sin Obra Derivada 


\title{
Contexto sonoro expandido en el pensamiento equinoccial contemporáneo' \\ Expanded Sonic Context in Contemporary \\ Equinoctial Thinking
}

\author{
Norberto Bayo ${ }^{2}$ \\ Universidad Nacional de Educación a Distancia \\ Universidad de las Artes, Guayaquil \\ España / Ecuador
}

Recibido: 23 de agosto del 2017 Aprobado: 19 de setiembre del 2017

\begin{abstract}
Resumen
Son múltiples las propuestas creativas a favor de una hibridación parametral del sonido y sus múltiples relaciones con el lenguaje, como respuesta a la jugosa pregunta de cómo escuchamos, y a la famosa disputa cuánto de Arte lleva consigo Ciencia y viceversa. El ejercicio de lo sonoro debería suceder en un espacio de reconciliación semiótica entre escritura, memoria y escucha. Enrique Males (Ibarra, Ecuador, 1942) y Mesías Maiguashca (Quito, Ecuador, 1938) toman muestras, colores y recursos de los territorios andinos para brindarnos un duelo que, en medio de la abstracción y la figuración sonora, pretenden vehicular suficientes estímulos retóricos conscientes en el fenómeno acústico expandido. La experiencia de la composición contemporánea y del ejercicio de la interpretación sonológica apelan a un pozo emocional común del que se desprenden y modifican las posibilidades de nuestra ingenuidad. Defenderemos una escucha asociada al encuentro de los discursos de lo andino y lo colonial. La obra de estos artistas manifiesta que es posible construir memoria y reivindicar contextos compartidos.
\end{abstract}

Palabras clave: estética; paisaje; composición; música; equinoccial

1 Investigación asociada a la tesis doctoral "Estética declinada: institución y decolonialidad en el contexto de lo sonoro" que actualmente desarrollo en la Universidad Nacional de Educación a Distancia (UNED, España); agradecimiento a los doctores Jordi Claramonte y Miguel Álvarez-Fernández, co-directores de la tesis.

2 Docente de la Escuela de Artes Sonoras y Director de la Jefatura de la Nivelación Emblemática de la Universidad de las Artes, Ecuador. Máster en Estética y Gramáticas del Arte Contemporáneo por la Universidad Autónoma de Barcelona. Doctorando en Estética por la Universidad Nacional de Educación a Distancia (UNED, España). Correo electrónico: norberto@lacosacultural.com

ESCENA. Revista de las artes, 2018, Vol. 78, Núm. 1 (julio-diciembre), pp. 83-97. ISSN 2215-4906 


\begin{abstract}
There are multiples proposals in order to a parametrical hybridization between sound and their multiples relations with language, as an answer to the juicy question about how we listen, and the famous argument about how much Art is within Science and vice versa. The exercise of sound should happen in a space of semiotic reconciliation between writing, memoring and listening. Enrique Males (lbarra, Ecuador, 1942) and Mesías Maiguashca (Quito, Ecuador, 1938) take samples, colors and resources from the Andian territories to give us a mourning that, between sonic abstraction and figuration, want to drive enough conscient rhetorical stimuli in the expanded acoustic phenomenon. The experience of contemporary composition and the exercise of sonologic interpretation appeal to a common emotional sediment from where the possibilities of our ingenuity are detached and modified. We will defend a listening-in linked to the meeting between andinean and colonial speeches. These artist's work shows that it is possible to build and claim shared contexts.
\end{abstract}

Keywords: aesthetic; landscape; composition; music; equinoctial 


\section{Introducción: una nota estética}

En nuestra actualidad, los espacios de creación compartidos encuentran en las prácticas artísticas una experiencia de actualización permanente de los procesos de identidad asociados a un contexto, discursivamente, en construcción. En este territorio equinoccial confluyen el paisaje andino y el pasado colonial, y la hibridación dependerá del tipo de literalidad que incorpore en su proyecto creativo. El espectador será agente social en permanente formación. John Dewey (1859-1952), filósofo y pedagogo estadounidense ayudó a repensar hace más de una centuria el tipo de compromiso simbólico en clave intercultural:

Si la educación es vida, toda vida tiene, vista desde fuera, un aspecto científico, un aspecto de arte y cultura y un aspecto de comunicación. ... El progreso no está en la sucesión de estudios, sino en el desarrollo de nuevas actitudes y nuevos intereses respecto a la experiencia (Dewey, 1997, p.47).

John Dewey (1997) propone la búsqueda de un descubridor que transforma ${ }^{3}$. Pensar en los muros de nuestra defensa particular, con base en unas condiciones orgánicas, permite garantizar el sentido de conservación del que parte cualquier civilización. Ser individuo implica poder imaginar un mundo en su posibilidad efectiva. Es nuestro cuerpo racional el que permite transportar las actitudes empiristas que queremos planificar hacia el plano de la imaginación. Deberíamos, músicos y musicólogos, garantizar una escucha responsable del fenómeno andino como primera propuesta de paisaje en las instituciones culturales para favorecer la verdadera mediación con el espectador.

Ciento veinte años resuenan en cómo la experiencia progresa en forma de cultura, de política y de praxis educativa. Esta tríada fundamental afecta al comportamiento en un mundo civilizado y parece dedicar poco recorrido mental a la experiencia de delimitar el espacio del planteamiento de lo vivido, al menos en su apariencia más inmediata. Lo que aquí anunciamos es un sinfín de posibilidades creativas al relacionarnos con el medio musical, sea este contenido, estructura, apariencia o narración. Deberíamos responsabilizarnos de los procesos que somos capaces de imaginar y de los canales de los que la propia imaginación se ha servido para tal efecto.

${ }^{3}$ La propuesta metodológica que Dewey desarrolla se divide en cinco fases: Sugerir; Desarrollar; Observar; Reelaborar; Verificar. La propuesta de llegada que Dewey propone debemos entenderla como un lugar mental donde desplegar el planteamiento transformador. El elemento transversal vendrá desmarcado por su "otra" naturaleza, orgánica, cuyo mensaje radica en los actos performativos entre organismo y ambiente en el tránsito del desequilibrio y equilibrio (Abagnanana y Visalberghi, 2012).

ESCENA. Revista de las artes, 2018, Vol. 78, Núm. 1 (julio-diciembre), pp. 83-97. ISSN 2215-4906 
John Dewey (1997) afirma: "las emociones son el reflejo de las acciones" (p. 53). En su interés por renovar una hipótesis original, localiza el espacio común en la capacidad de imaginar. Así, puede llevar a cabo la sintonía entre el espíritu de grupo y el tiempo para la ejecución de las soluciones originales. El círculo histórico andino nos permite descubrirnos en una relación virtual que es capaz de pensarse a sí misma como una latitud y que implica una nueva concepción de lo sonoro en su vínculo con el imaginario común en el progreso social.

Si la educación es un proceso de vida, esta debería responder a una transacción de todo lo que el sujeto conoce. Aquellos que nos dedicamos a la enseñanza del fenómeno de la escucha, no solo transmitimos expectativas, hábitos, esperanzas o temores. A estos resultados debemos añadir su foco de origen o perturbación de los estímulos sensibles en nuestro siglo XXI: la llamada del ruido y su asunción en el silencio. ¿En qué actividades apoyarnos para que garanticen un proceso para la formación de oyentes en este presente? ¿Cuáles son los repertorios que ayudan a pensar los límites de la cultura como un medio en el que se reconozca las experiencias artísticas? ¿Qué disposiciones son las puestas en escena para favorecer un diálogo de las prácticas sonoras en el pensamiento equinoccial en nuestra sociedad del siglo XXI? Si la escuela es institución social como afirma Dewey, esta nos permitirá dar efectividad a los medios existentes que rondan por lo ya vivido. ¿Qué producimos? ¿De qué manera podemos favorecer la personalidad individual creativa? ¿Cuál es la mejor forma de proyectarnos en el paisaje? Acerca del contexto sonoro expandido destacaremos el tipo de respuestas que dialoguen con un tipo de reconocimiento que el propio contexto es capaz de generar.

\section{La transculturalidad como actitud mental}

El espacio de lo sonoro en América Latina permite compartir un espacio virtual topográfico en su afán por construir los escenarios posibles. La memoria del sujeto andino permite recordar estos territorios desde la lógica de la imaginación, saturación y desbordamiento. La memoria y el espacio aparecen constantemente en teorías sobre la identidad, la nación y la ciudadanía en Latinoamérica. De manera particular, para la región andina se emplea la huella de lo mestizo cuyo límite y diferencia se asume, colectivamente, en aras de la pluralidad indigenista. En Buscando al Inca desde los nuevos debates y La ideología de la transculturación, Mabel Moraña (2010), académica y ensayista uruguaya, pone de manifiesto el trasfondo heterogéneo y transnacionalizador del territorio andino.

Por un lado, encontramos la necesidad de repensar los modelos de distribución literarios y artísticos de los últimos 700 años a favor de una ciudad letrada de cierto aire utópico. El aspecto social será el vehículo de una estructura económica ya establecida y el 
pretexto de lo mestizo un modelo propio de la región. Lo colonial informa sobre la especificidad sociocultural de ese contenido en forma de experiencia. El territorio virtual necesario para ello partirá de las subjetividades de una narrativa neorregionalista procomún hacia el régimen de la dominación. Ángel Rama (2008) detecta, en el testimonio de la dialéctica entre amo y servidor, un pluralismo del límite de la idea del futuro burgués hispanoamericano: "la República heredó la situación establecida por la colonia y la perfeccionó, situándolo en un marco clasista" (p. 146).

Por otro lado, debemos relacionarlos con el contenido ficcional integrador de los principios de la idea del mestizaje. La condición de lo mestizo junto con la actitud del migrante ficcionalizará lo incaico como un espacio epocal contracultural. La otredad del individuo colonial deviene como organización social y control político. La colonialidad en la modernidad provoca de manera incidental una respuesta hacia la ideología del proceso en el relato de lo mestizo, de lo multidisciplinario. La memoria del Inca permanece hoy como un sujeto migrante de una diáspora que se planifica a partir de la integración de imaginarios, modelos y costumbres (Ortega, 2015). Repensar la interculturalidad desde lo equinoccial permite trazar una ruta para la práctica identitaria de escucha. Un análisis profundo sobre las relaciones interculturales en la práctica andina permitirá difuminar las mutables fronteras del Ecuador.

\section{Límite y territorio}

Enrique Males (Ibarra, 1942) es un músico autodidacta de la región andina de Ecuador. Lleva más de cuarenta años de actividad cultural nacional e internacional. Su trayectoria musical se ha venido desarrollando, paralelamente, a la de construir un sujeto comprometido con la vida social y política que huye de la identidad desmarcada del mestizaje. El asesinato del expresidente de Chile, Salvador Allende (11 de septiembre de 1973), supuso un punto de inflexión para el futuro de su carrera musical. Ese inconformismo, rabia e impotencia llegaría a transformarse en un canto sujeto a la lucha y a la unión, a la protesta. La nueva estética de la canción de autor, así como su voz y puesta en escena, ayudan a dar a conocer nuevas formas en la percepción de lo sonoro. El propio Males narra en el documental dirigido por el director Carlos Naranjo (2009), Enrique Males, lo esencial, su relación con lo cotidiano:

Me desarrollé a mi manera. Me forjé a mi manera. Me eduqué a mi manera ... Soy un autodidacta de la música y de la vida; no tengo estudios académicos de ninguna clase, pero mi mejor aprendizaje lo conseguí en el transcurso de la vida, en los caminos que recorrí. ... La identidad está en el espíritu, en la mente, en las acciones. Hay indígenas con mente y actitud de blanco; hay mestizos con espíritu, convicción y lucha indígena (Males citado en Naranjo, 2009, min. 18-23). 
Los procesos de aculturación que Males sufrió en su etapa escolar primaria determinarían su obsesión por vincular el origen de la creación a un orden de contenido social. Lo cotidiano, aquí, sí debemos relacionarlo a las estrategias que la música ofrece al compartir las fronteras mentales y entender ciertas lógicas precolombinas en los mismos yacimientos o en las comunidades custodias de culturas ancestrales. El valor de la cultura popular se traduce aquí a un sinfín de experiencias estéticas sonoras y de las imágenes mentales que somos capaces de recrear. El ejercicio de la comunidad, la vinculación del objeto sonoro en el carácter dinamizador de conocimiento de experiencias desde un empirismo posible en el aprendizaje de las formas y mensajes ancestrales. Este ejercicio permite remontarse a un tipo de configuración mental ad hoc de una sustantivación sonora, a partir de los pingullos, rondadores, silbatos, sonajas de caña, barro, calabaza, mate, entre otros.

Las sucesiones de gacetillas de prensa a lo largo de cuarenta años ilustran un Enrique Males versátil y que propone significantes posibles de un imaginario en construcción permanente hacia un ser transcultural. Cada disco puede responder a un enigma casuístico fenomenológico de relaciones interculturales. El sujeto que propone Males decide permanecer en el grado cero mental y pone frente a él las múltiples perspectivas de los lugares de enunciación. Los sonidos que aquí discriminamos no pretenden describir ninguna catedral sumergida ni descubrir un espacio constelar, sino poner de manifiesto que investigar en y para las artes implica un compromiso con lo social y lo político; un conocer entre las tradiciones y las experiencias plurales de eje contextual. Como espectadores tenemos el reconocimiento del otro para validar que los procesos transculturales pueden alcanzar un grado de autonomía capaz de vehicular la experiencia a partir de la práctica discursiva. Los mecanismos de los que la institución se sirve para reorganizar los modos de planteamiento disciplinar, al menos en Artes, se alejan de la práctica empírica como si de esta no se pudieran aprehender patrones sociales y culturales, que conviven ya con nosotros unos cientos de años por esta región andina. La obra de Enrique Males abrirá el diálogo para repensar un lugar posible de enunciación de carácter transversalizador; un sujeto que se debate entre lo indígena y lo mestizo, lo criollo y lo moderno, lo colonial y lo nacional.

Ahora, la relación con lo colonial habla de un viaje mental que tiene como punto de llegada el ritual: cierta dominación en las estructuras melódicas más claras, repeticiones de patrones, variaciones -y la misma recurrencia a lo ceremonial- sean estas de carácter festivo, solemne o dramático. Toda una tecnología expandida que el barro, la calabaza y el bambú transfieren a la necesidad de dominio de lo sonoro. El sujeto está presente en la lógica del mensaje dirigido, transitivo, recurrente a la idea del rapsoda. La topografía es más evidente aquí porque, el estar presente en ese hecho, nos hace participar del sentimiento que 
expresa el otro particular; una especie de medio trasmisor de un repertorio oral que se resiste a ser compartido hasta en el espacio de lo privado. Los efectos sonoros concretos, de los que se apoya en esta segunda parte, denotan más que connotan, hablan del contexto más que de una actitud compartida, mucho más separado el indígena del mestizo, por supuesto.

Por un lado, obras como el trabajo discográfico Naupamanta Kaynamanta Kunankaman (Males, 1997) nos pueden ayudar a pensar una cierta narración de la memoria con la materialidad de los instrumentos y su relación con las técnicas de interpretación. La presencia del aire y el agua en los instrumentos seleccionados sustituyen cierta naturaleza con alma ancestral. Palos de agua, tubos, vasijas y pieles tensadas ayudan a sentir toda la energía que condensó un espacio abierto al universo de lo sonoro. En una primera parte, raíces y vivencia cotidiana se esbozan como lenguaje del trabajador. La relación física requerida alcanza los efectos del paisaje material de las lógicas precolombinas. Ser comunidad implica compartir una experiencia afín a un sentimiento de acogida, sea empatía (por su carácter positivo), sea un conocimiento que apele a lo nuevo. Chaquiñan (Camino de pie), Cayachina (Llamadas), Naten (Zumo de tabaco). Estos son los primeros temas que van construyendo una legitimidad tímbrica y percutiva al paisaje equinoccial. Quienes nos esperan al final del camino son caminantes que retoman su trayecto hacia el origen. Ese punto de encuentro entre costa y Amazonía.

Por otro lado, en Semillas de Identidad (Males, 2007), que responde al encuentro con el poeta Jaime E. López Cobo, se nos presenta como un espacio para la experimentación de un latir andino. Enrique Males propone la rapsodia por la rapsodia y la belleza por la cultura a través de poesías, canciones y pasillos que transforman el contraste étnico, social y generacional. Nos permite incidir sobre la actitud creativa de esa experiencia concebida. Nostalgia, inmediatez, inevitabilidad son las constantes para la distribución de lo nacional. La tecnología de este viaje queda emplazada en el fenómeno de la comunicación retórica, que observamos, por ejemplo, en el guiño al avillancicado sanjuanito contemporáneo, que permite recordar aquella transformación que sufrió la idea del discurso reordenado.

Las formas culturales que aquí asoman acercan un espacio bisagra entre la Gran Colombia territorial y la angustia del conflicto del Virreinato del Perú. Ecuador, debido a su latitud grado cero, transita los grados uno, positivo y negativo, en un conflicto territorial desde la época colonial hasta hoy día. No solo debemos destacar la valiosísima obra de Enrique Males como cantautor y exponente de la canción protesta, sino que debemos prestar, quizás, mayor atención a su repertorio más conocido como música ceremonial. En Amauta del Canto y la Armonía, por ejemplo, Males (2007) invoca al pasado y a las culturas a través de lo ancestral. Hay un pequeño matiz de diferencia entre el pasado cultural andino como 
lugar de denuncia y la temporalidad aquí ahora presente; con el pasado precolombino que provoca la espacialidad de un paisaje que está por interpretar. Aquí no es necesario hablar de ironía ¿es un territorio confiable en la proyección de lo tradicional como un lugar de enunciación? Debemos observar como los procesos de descolonización y reidentificación en los territorios expandidos posibilitan consensos entorno al compromiso con la comunidad.

\section{La equinoccialidad como actitud de encuentro}

Esteban Ponce Ortiz, ensayista y literato ecuatoriano, acaba de editar para la Universidad de las Artes de Guayaquil (Ecuador) el volumen Grado cero: la condición equinoccial y la producción de cultura en el Ecuador y en otras longitudes ecuatoriales. Para el cual reunió a un grupo internacional de intelectuales con el fin de reflexionar la condición de mapa como lugar de encuentro. En su artículo introductorio La construcción simbólica de lo equinoccial en lo nacional y en una globalidad otra nos propone tímidamente el deseo de ser que se desprende de una línea plural intercomunicada con carácter transferencial.

El espacio meridional y equinoccial se convierte en un territorio de contacto no únicamente entre los hemisferios, sino el umbral en el que las tensiones del lenguaje, del pensamiento y del quehacer histórico alcanzan sus niveles límite, y es la mirada del observador, o del lector o del analista, la que inclina la tensión hacia un lado u otro de los hemisferios, y no necesariamente es el poema, la pieza de cerámica o al cuadro el que se esté ubicando en uno u otro lado de esas tensiones, sino que es la mirada de observador la que lo inclina hacia uno u otro hemisferio (Ponce, 2017, p. 36).

Aquí notamos la diferencia que debemos tener presente a la hora de describir el paisaje como actitud y mapeo del encuentro intercultural y pluriétnico. Sin querer realizar un estudio antropológico sobre los escenarios posibles para plantear las estructuras sonoras afines a una responsabilidad social y política con una región rica y pluridiversal, sí consideramos la idea de un mapa comunitario que se ha venido desarrollando en los estudios interculturales para el pensamiento decolonial bajo la figura de Abya-Yala ${ }^{4}$. Ponce (2017) parece preguntarse sobre las razones que dieron lugar a patrimonializar los paisajes culturales transversalizadores, a partir de la experiencia de la escucha. El paisaje cultural en construcción que se nos propone parte de dos momentos de reflexión inter/multi: un primero que apela a la mitad del mundo y otro que ocupa la línea del pensamiento transversalizador

${ }^{4}$ La perspectiva crítica que la autora y editora Catherine Walsh propone como lugar de origen para la enunciación de las transferencias culturales en la región andina que mantienen aún custodiadas las experiencias colectivas que ayudan a transformar lo equinoccial previo al contacto colombino (Walsh, 2012).

ESCENA. Revista de las artes, 2018, Vol. 78, Núm. 1 (julio-diciembre), pp. 83-97. ISSN 2215-4906 
orbitante $^{5}$. Lo que aquí ponemos en evidencia es la idea de un sujeto creador que propone un espacio potencial creativo que se debate entre lo abstracto y lo ancestralista geométrico. La forma creativa que muestra la imaginación se suma a la resistencia contra la hegemonía de la propia forma creativa: actitud y necesidad del contenido creador transferidas como memoria de la materialidad y de los avances tecnológicos y los mecanismos de distribución culturales contemporáneos (Walsh, 2003).

\section{Tiempo y territorio}

Mesías Maiguascha (Quito, 1938) comparte públicamente sus estudios, trabajos, escritos en su web de artista ${ }^{6}$. Aunque actualmente, reside en Alemania su influencia en Ecuador se manifiesta tanto en las instituciones como en colectivos independientes que gestionan conciertos, exposiciones y encuentros. Es considerado como el primer ruidista de la región andina ${ }^{7}$. También tuvo una infancia llena de tensiones y hostilidades, pero encontró en la música un lugar para su desarrollo integral hasta hoy. Su formación inicial en el Conservatorio Nacional de Quito y la educación "clásica" como pianista es bien contrastante con su experiencia norte/sur en la década de 1960, cuando conoció a Henry Cowell (1897-1965) en Nueva York, por un lado y a Alberto Ginastera (1916-1983) del Instituto DiTella en Buenos Aires, por el otro. Su experiencia transatlántica se consolida cuando pasa a formar parte del estudio WDR, en Colonia, como técnico asistente de Karlheinz Stockhausen (1928-2007). En múltiples ocasiones al revisar lo dicho antes, Maiguashca partía, tempranamente, de un espíritu transcultural conciliador:

${ }^{5}$ Esteban Ponce propone como línea de investigación la "Equinoccialidad y Cultura" en la azarografía equinoccial de un paisaje cultural distópico como potencialidad simbólica unificadora de lo "diverso" a partir de nuestra mirada: "asumo como punto de partida de esta reflexión sobre lo equinoccial como paisaje digno de ser heredado, la misma perspectiva con que los analistas de UNESCO abordaron la espacialidad andina como una constelación cultural o una azarografía (una gráfica de un azar), un mapa de registros múltiples que adquiere unidad a partir del capricho de la mirada del observador, a partir del capricho por dar una forma a los múltiples paisajes culturales que ocupan esa línea que cruza la República del Ecuador, La América del Sur, el centro de África y el extremo del sur de Asia; que flanquea con innumerables islas del Pacífico y por las Galápagos cierra la circunferencia planetaria" (Ponce, 2017, p. 25).

${ }^{6} \mathrm{http}: / /$ www.maiguashca.de

${ }^{7}$ Cuenta con una red de trabajo sobre Objetos Sonoros en Quito muy significativa, de los que destacar: RedCe (Red de Compositores Ecuatorianos), Centro Experimental Oído Salvaje, Colectivo Central Dogma y Red Ruidistas.

ESCENA. Revista de las artes, 2018, Vol. 78, Núm. 1 (julio-diciembre), pp. 83-97. ISSN 2215-4906 
'El recuerdo más antiguo que tengo de mi infancia es salir de mi país y no regresar, he tenido éxito; 40 años después veo una realidad que llamé la mía por 20 años como a través de un vidrio, desde una realidad que tampoco es mía, percibo otra a la cual ya no tengo acceso'. Eso escribí en 1982, pero continúa siendo la descripción más precisa de mi destino humano y artístico, para expresarlo de otra manera, este ha sido el salir de una cultura, el de peregrinar por otras, el de asentarme en una tercera, sin poder efectivamente incorporarme y de no poder volver a la primera, en alemán se dice, estar sentado entre dos sillas (Maiguashca, 1989, p. 56).

Por muchas razones que no podemos abarcar en este ensayo, Ayayayayay (1971) es una de las obras, por no decir la más, emblemáticas de Maiguashca. Principalmente, por su vinculación con un sistema de escucha triplemente contextual. Primero, porque el proyecto narrativo sobre el que se apoya el registro/muestreo del material sonoro usa la naturaleza y costumbres andinas que comparten tiempo y espacio en el presente, resumida en forma de experiencia "existencial". Segundo, porque la escucha que propone Maiguashca está llena de metáforas reconocibles con una fuerte carga de responsabilidad, denuncia social y política. Tercero, porque el vínculo entre el compositor-intérprete y el oyente con estos nuevos modos de estar con el material sonoro (los modos de conocer y de nombrar nuevas condiciones en el sistema de la escucha) está mucho más abierto y menos dirigido al entendimiento de un nuevo tipo de estructura musical sobre la concepción de paisaje que sus antecedentes electroacústicos occidentales.

La cinta electrónica desata su propia dimensionalidad en el acto de ser escuchada. La experiencia de expandir el espacio y tiempo de lo sonoro, a partir de mecanismos electrónicos y magnéticos ayuda a pensar en un terreno fértil posible. La cinta magnética es unidad contrastante en ese juego sin fin de manipulación de los elementos. Así, cede su lugar al espectador en el conocimiento de sus constantes dialécticas: pailas metálicas, piedras de moles o rondadores andinos sirven para dotar al objeto de un encuentro con la propia experiencia de habitar ${ }^{8}$.

El concepto de geografía sonora le sirve al mismo compositor para referirse a diferentes trabajos. Los trabajos que se desarrollan conceptualmente, como geografías sonoras invitan al espectador a que transite el espacio del concierto para territorializar sus sentidos y para ser conscientes de a qué terreno pertenece. Lo que aquí nos interesa, conceptualmente, es el lugar de enunciación de estilo que parece responder de manera más directa a un efecto inmediato dérmico como metáfora de un sistema de escucha que la cultura está aún por evidenciar. A finales del siglo XX, se celebró el molesto acontecimiento del

${ }^{8}$ La obra de Mesías Maiguashca puede ser planteada bajo un paraguas policonceptual sujetos al territorio: como objetos sonoros, como geografías sonoras y como órbitas discursivas (Kueva, 2013). 
V Centenario del Descubrimiento de América. La celebración en occidente debería haber superado el posible efecto exotizante que sobre lo andino se desprende. Técnicamente, la flauta aparece resuelta como las analogías vocales: las técnicas expandidas que permiten el tubo armónico soplado abierto nos enfrentan con un mensaje de elasticidad que permite el cuerpo acústico, de carácter magnético. Un nuevo norte se aparece como nuevo espacio para la mirada del fenómeno acústico en el contexto referencial:

Tengo una UTOPÍA: Creo que lo único que puede 'civilizar' al mundo y a la avalancha de la 'globalización' que se nos viene encima es la Revolución Ética. Creo que la próxima revolución será la Revolución Ética. Será una revolución sin sangre, sin violencia, pues tendrá que nacer en el silencio de cada uno. Pero necesitaremos de voces inspiradas que guíen, que sinteticen, que generen el 'cómo'. Pues el principio es simple: el principio económico debe subordinarse al principio ético y ponerse a su servicio y no lo contrario (Maiguashca, 2001-2008, p. 5).

Hablar de espacio en la obra de Mesías Maiguashca implica expandir un trazado virtualizador de experiencias que se transforman, emocionalmente, en el medio resonador. Por ejemplo, los trabajos del ciclo Reading Castañeda (Maiguashca, 1997) parten de una capacidad extensiva en el fenómeno acústico del objeto sonoro expandido. Aquí, a diferencia de Enrique Males, no es la vinculación transcultural el resultado de las tensiones metafóricas entre poder y represión, provocadas con la sensación de orfandad ideológica a partir de la muerte de Salvador Allende (1908-1973), sino la posibilidad de evasión y responsabilidad con la relación entre los medios del mensaje. Es decir, el lugar de la conciencia sonora como ser unificador. Concretamente, en la pieza El Oro, las referencias "plata" y "oro" que resuenan del discurso de Guaman Poma de Ayala (1534-1615) se vuelven agresivas a la mirada del occidental responsable en una sociedad autoreferencial. Veamos, pues, los resultados psicoperceptivos de la geografía sonora: la naturaleza mística a la que apela esta obra participa del ritual de la cueva, devenida a su naturaleza ancestral, en un lugar intermedio entre la realidad y la fantasía, entre el mito y la lógica, entre la locura y la cordura.

Sin embargo, hablar del tiempo en la geografía sonora de Mesías Maiguashca significa no solo encontrarnos con la naturaleza sonora vivida, sino que es, además, una invitación a pensar en una panarquía de experiencias comunes a partir de la escucha. Apropiarse de las literalidades que ha construido y destruido la modernidad, a ambos lados del océano Atlántico nos ofrece la posibilidad de pensar un centro andino en constante transformación alegórica. En La canción de la Tierra (Maiguashca, 2013) condensa la experiencia de la obra total, no solo desde el punto de vista de la composición, sino como encuentro intelectual con el espectador. En un centro ceremonial ancestral como es el parque del Itchimbía, en Quito (que denota todo el carácter espiritual que va a salir al encuentro de uno mismo a la salida del sol durante el Inti Raymi), aparecen lenguajes, sensaciones e interacciones que dan prioridad 
al sentido de la escucha. La geografía sonora permitió transitar la experiencia del adentro y el afuera físico del espacio del concierto, concreto, para facilitar la "escucha" de esa puesta de sol.

Los fenómenos acústicos expandidos que el equipo de Maiguashca interpretó en el Palacio de Cristal del Centro Cultural Itchimbía proponían transitar física y mentalmente por los tres mundos de la cosmovisión andina, dándole bienvenida al dios Sol. El compendio sinfónico que propone La Canción de la Tierra parte de la reconciliación con un ser espiritual interno, resonador, inconsciente del transitar con lo originario; un estar emplazado en el equilibrio sobre una línea que divide, no solo el planeta, sino que aleja todo lo físicamente posible del centro magnético de la Tierra. El concierto se componía de una orquesta de instrumentos andinos, una banda sinfónica, un coro mixto y una instalación sonora sobre los fenómenos físicos estacionales. Mesías sustituyó la paleta de colores por la condensación del mensaje político de dominación y exterminio ante una sinrazón estética de la que, incluso hoy, nos cuesta emanciparnos. Maiguashca (2013) se propone intercambiar los lugares con el oyente, para responsabilizarnos de los medios de distribución de los ideales nacionales y populares transitables en el presente. Maiguashca discriminó en La Canción de la Tierra de Gustav Mahler (1860-1911) un ciclo de canciones en forma de sinfonía; la invitación para caminar hacia lo desconocido en el transitar de la vida humana: anhelos, reencuentros, metáforas y pensamientos, contextos, al fin y al cabo.

\section{A modo de conclusión}

Actualmente, las instituciones relacionadas con el ejercicio de la música -sean estas formativas, de conservación y/o exhibición- encuentran el carácter situado que demandan los procesos actuales de relación con lo sonoro. La incorporación de los laboratorios transmedia, así como los avances estilísticos en el encuentro con lo popular (músicas urbanas, por ejemplo) forman parte de nuevas dimensionalidades afines a nuevos tipos de experiencias musicales. La mediación será el lugar ideal para poner en práctica el verdadero encuentro orgánico y el desarrollo de las capacidades creativas como vehículo de transmisión de la propia cultura. Las viejas estrategias de distribución cultural suponían, para Enrique Males y Mesías Maiguashca el lugar para plantear una posible panarquía ${ }^{9}$ en el encuentro

9 Panarquía como un ejercicio práctico de relaciones que la teoría de la estética modal propone. Esta teoría pretende definir el tipo de éxitos y relaciones que la filosofía del Arte encuentra en su convivencia con la performatividad social y política: "obviamente nuestro reto es mantener presente todo el esquema en su funcionamiento conjunto, con todo ese juego cruzado de tensiones entre los cuatro modos relativos y con las diferentes fuerzas centrífugas y centrípetas que operan desde y hacia lo efectivo o lo inefectivo" (Claramonte, 2016, p. 156). 
con la escucha. El estudio de grabación será el resultado de un afinado instinto que permite conducir todo un sistema simbólico basado en el tipo de experiencia:

El arte es una cualidad que impregna la experiencia; no es, salvo por una figura del lenguaje, la experiencia misma. La experiencia estética es siempre más que estética. En ella un cuerpo de materias y significados no estéticos por sí mismos, se hacen estéticos cuando toman un movimiento ordenado y rítmico hacia su consumación. El material mismo es ampliamente humano (Dewey, 2008, p. 369).

El contexto sonoro expandido cuenta con la evidencia de un cruce entre tensión y conflicto, que es liberado a partir del encuentro. Las estructuras de las propuestas irán siendo moldeadas por un propositor sonológico, con nuevas responsabilidades en el ejercicio político y social. Este acercamiento político y social, que se propone como pensamiento estético integrador, quizás permita definir el tipo de equilibrio entre responsabilidad y práctica artística en el siglo XXI.

El pensamiento equinoccial contemporáneo permite pensar en la naturaleza del tiempo, del espacio y los límites del territorio, de la experiencia que se intelectualiza de una o tal manera, física y/o mental. Permite desarrollarnos como seres emocionales hacia una verdadera mediación integral, culturalmente, hablando. Imaginemos las posibilidades y mejoras de un proceso mediador en el territorio equinoccial: por un lado, la creciente transculturalización que sufre el espacio sonoro latinoamericano en su responsabilidad social y política en el presente. Por el otro, la hibridación de los nuevos medios y la incorporación de la electrónica como un tiempo reconciliador con una naturaleza transhumana, cuya narración sigue pendiente. No se trata aquí de cerrar un círculo, ni de superarse en el trascurso de lo vivido, sino de una arriesgada decisión creadora, responsable de una herencia contextual del sonido y espacio dedicados a la imaginación. Nuestra misión será, pues, la de garantizar un territorio naturalista afín a un espíritu antireduccionista de sistemas de creencias; nociones e intereses; aceptaciones y rechazos sugeridos por el hábito y la tradición. De esta forma, enriquecer el discurso decolonial a favor de un paisaje afín a una estética modal en Latinoamérica en relación con lo sonoro.

\section{Referencias}

Abagnanana, N. \& Visalberghi, A. (2012). Historia de la pedagogía. México: Fondo de Cultura Económica.

Claramonte, J. (2016). Estética Modal. Madrid: Tecnos.

Dewey, J. (1997). Mi credo pedagógico. León: Universidad. 
Dewey, J. (2008). El arte como experiencia. Barcelona: Paidós.

Kueva, F. (Ed.). (2013). Mesías Maiguashca. Los sonidos posibles. Quito: Hominen.

Maiguashca, M. (1989). La obra de Mesías Maiguashca. Opus, Revista de la Musicoteca Central del Ecuador, (32), 45-56.

Maiguashca, M. (1997). Reading Castañeda. Recuperado de http://www.maiguashca.de

Maiguashca, M. (2001-2008). El quehacer estético, mi quehacer estético. Recuperado de http://www.maiguashca.de

Maiguashca, M. (2013). La canción de la tierra, notas al programa. Recuperado de http:// www.maiguashca.de

Maiguashca, M. (2013). La canción de una Tierra, un itinerario. Recuperado de http://www. maiguashca.de

Males, E. (1997). Naupamanta Kaynamanta KunanKaman [CD]. Quito: Enrique Males.

Males, E. (2009). Amauta del Canto y la Armonía [CD]. Quito: Casa de la Cultura Ecuatoriana Benjamín Carrión.

Males, E. (2007). Semillas de Identidad [CD] Quito: Enrique Males.

Moraña, M. (2010). La escritura del límite. Madrid: Iberoamericana.

Naranjo, C. (director). (2009). Enrique Males, lo esencial [DVD]. Quito: Casa de la Cultura Ecuatoriana Benjamín Carrión.

Ortega, A. (Ed.). (2015). Mabel Moraña. Territorios y Forasteros: retratos y debates latinoamericanos. Guayaquil: Universidad de las Artes.

Ponce, E. (Ed.). (2017). Grado cero: la condición equinoccial y la producción de la cultura en el Ecuador y en otras longitudes ecuatoriales. Guayaquil: Universidad de las Artes.

Rama, A. (2008). Transculturación narrativa en América Latina. Buenos Aires: Ediciones El Andariego.

Walsh, C. (Ed.). (2003). Estudios culturales latinoamericanos. Retos desde y sobre la región andina. Quito: Universidad Andina Simón Bolívar / Abya-Yala.

Walsh, C. (2012). Interculturalidad crítica y (de)colonialidad. Ensayos desde Abya Yala. Quito: Abya - Yala. 